\title{
Experiment in postgraduate psychiatric education: students teaching students
}

\author{
J. Guy Edwards
}

Psychiatric trainees in the Wessex Region gove their own lectures on an MRCPsych course and recelved feedback on their performance from their peers. The form and content of the lectures were olven high ratings and the presentations were considered at loast as good as those given by more experienced lecturers. The experiment can serve as a model to supplement existing courses for trainees and as a 'do-lt-yourself' form of education for areas and countries that have inadequate access to centres for postgraduate education.

This paper describes an experiment in postgraduate education in which psychiatric trainees in the Wessex Regional School of Psychiatry (WRSP) took the place of lecturers on Part II of the MRCPsych course and delivered their own lectures. Feedback on their performance was obtained from their peers.

The WRSP was established in 1964 and to begin with it was based at Knowle Hospital, Fareham. When the Department of Psychiatry (DOP) at the Royal South Hants Hospital was opened in 1975 the facility was transferred to the DOP site.

Trainee psychiatrists (senior house officers and registrars) based in hospitals throughout the Wessex Region attend the Regional School on a day release basis. The course is divided into Parts I and II and covers all aspects of education relevant to the MRCPsych examinations. Thus, it includes lectures on all the basic sciences related to psychiatry and all aspects of clinical psychiatry. Lectures and seminars are normally given by members of the academic staff of the University of Southampton and consultants in the Southampton and South West Hampshire and neighbouring health authorities.

\section{The study}

Twelve of the postgraduate students on the membership course ( 8 men and 4 women; 9 native born and 3 from overseas) were invited to participate in the experiment. The rationale for the study was explained and they were asked to lecture to their fellow students for 40 minutes on the 12 subjects on which I would otherwise have lectured, namely anxiety disorders; affective disorders; schizophrenia; general principles of psychopharmacology; drug treatment of anxiety, affective disorders and schizophrenia; unwanted effects of, and interactions with, psychotropic drugs; other physical treatments in psychiatry; assessment of clinical trials; and the application of the assessment method of trials to recent psychiatric publications.

Prior to the lecture each trainee was given advice on the relevant literature, asked to prepare visual aids in the form of handouts and/or overheads, and invited to rehearse his or her talk. Following the presentation the audience was encouraged to ask questions on the contents of the lecture for ten minutes, and then to give constructively critical feedback to the trainee on the form and style of the presentation for a further ten minutes. The audience was asked to rate in confidence the content and form of the lecture on an 8-point scale ranging from excellent' to 'useless' (see Table 1). They were also asked to compare the presentation with that of the (hypothetical) 'average' lecturer on the rest of the MRCPsych course. The rating options ranged from 'much better' to 'much worse' than the

Table 1. Ratings of lectures

\begin{tabular}{lcc}
\hline Ratings & Form & Content \\
\hline Excellent & 1 & 4 \\
Very good & 25 & 30 \\
Good & 25 & 29 \\
Satisfactory & 15 & 10 \\
Unsatisfactory & 7 & 0 \\
Poor, very poor, useless & 0 & 0 \\
Total & 73 & 73 \\
\hline
\end{tabular}


Table 2. Comparisons with 'average' lecturer in WRSP

\begin{tabular}{lr}
\hline Rating & \\
\hline Much better & 6 \\
Better & 33 \\
Same & 30 \\
Worse & 4 \\
Much worse & 0 \\
Total & 73 \\
\hline
\end{tabular}

average lecturer; these are shown in Table 2. An overview of the ratings was given to the postgraduate student who delivered the lecture without revealing the actual scores of his or her peers.

At the end of the experiment those attending a part or the whole of the course were invited to comment on what they liked and disliked about the sessions and how they could have been more helpful. They were also asked to rate how the sessions compared with the usual type of lecture and presentation on the course on a 4-point scale ranging from 'much prefer the experimental sessions' to 'much prefer the usual lectures/presentations'.

\section{Findings}

The number of students attending any one session did not exceed ten. Some of the sessions were held about the time that candidates were sitting the MRCPsych Part II examination; attendance at the Regional School at this time is usually lower than normal.

A large majority of individual ratings of both the form and content of the lectures (50 and 59 out of a total of 73, respectively) showed that they were regarded as very good' or 'good'. The form of only one lecture had a single rating of 'excellent' and there were only seven 'unsatisfactory' ratings. Overall, the content of the presentations was rated higher than the form. There were four ratings of 'excellent' and none in the 'unsatisfactory' to 'useless' range. A small majority (39) of ratings showed that the lectures were regarded as 'much better' or 'better' than those given by the 'average' lecturer on the MRCPsych course, while only four ratings suggested they were 'worse'.

The oral feedback given to the trainees by their peers following their presentation was helpful and constructive. Most trainees did not appear inhibited in offering criticism on either the form or content of the presentations and, when there was any hesitancy, it was easily overcome by stressing the importance to the presenter of constructive comments. In addition to the oral feedback trainees also wrote anonymous positive and critical comments on the rating forms. The latter did not add significantly to the oral criticisms confirming that the feedback was not markedly, if at all, inhibited.

Positive comments on the forms included such remarks as "clear, concise and allowing room for individual thought". "coped well with difficult subject", "very dry subject presented very clearly and thoughtfully - interesting to listen to" and "I came away having learnt something". Critical comments were made on trainees who read a part of their lecture, those who presented data already well covered in the literature with insufficient debate on the controversies revolving around the subject, and those who gave a "very bookish list of information" of limited clinical relevance.

Twelve trainees gave anonymous feedback on the course as a whole. Four of them "much preferred" and six "slightly preferred" the experimental sessions to the usual lectures given in the WRSP. Only two trainees preferred the latter. One of these thought that the experiment was unhelpful and should have been "outside our course time". Another criticism was the (deliberate) lack of senior input to the presentations, which the trainees suggested should have followed their own presentation.

Overall, there were more positive than negative comments. These spoke favourably about the relevance of the contents ("pitched at the right level"), the enthusiasm of the presenters, and the greater involvement of the group leading to "better concentration and interest". One trainee liked the idea of "juniors being able to do more work rather than being spoon fed", while another wrote: "At first it looked like a burden but once started it turned out to be an extremely useful experiment".

One presenter considered that "the prospect of peer assessment gave good incentive to research the subject, thereby encouraging learning". Another thought that the sessions were "helpful in clarifying and organising thoughts"; they encouraged the exploration and criticism of "myths" and the acquisition of presentation skills, "including overcoming the anxiety of speaking to colleagues". Yet another presenter spoke favourably about "being given some supervision about teaching techniques 
which you don't get elsewhere. I learnt a lot about the subject - much more than any other method of teaching".

\section{Comment}

Although this pilot study involved only a small number of trainees and lectures, the overall results show that trainee psychiatrists can give lectures of a high standard, with most ratings showing that they were considered to be as good as, if not better than, those delivered by more experienced lecturers. It is possible that the ratings might have been even higher than they were if more trainees had taken the opportunity of prior discussion and rehearsal of their talks. The extent to which this was done was limited, at least in part, by some of them working in hospitals distant from the WRSP and the experiment being held so close to the MRCPsych examination.

More formal lectures given by senior staff allow postgraduate students to witness a range of techniques developed over many years and to model their own performance on the best of these. An experienced lecturer may also stimulate interest in his subject, demonstrate ways of summarising essential issues and skillfully debate controversial points. However, some lecturers are less stimulating than others and it can be hard work for trainees to try to absorb the contents of a full day's programme of talks.

By contrast, the more active involvement of trainees in giving their own lectures, the close identification of the audience with the lecturer (knowing that each member's turn will soon come) and the giving of feedback by the group make the sessions more stimulating and the trainees more receptive. These, however, are statements of faith and more important are the high absolute and comparative ratings achieved.

Another advantage of 'do-it-yourself teaching is that courses can be set up, or supplementary lectures given, in areas - and more importantly in countries - that have limited, difficult or no access to centres for postgraduate education. Such DIY teaching, modelled along the lines described, could be even more productive if it were supported by contributions from a senior colleague. These could include, as well as guidance and feedback on rehearsals of the presentations, a demonstration on how to highlight the most important points and weight the evidence for and against contentious issues. A senior could also answer questions from the audience that the trainee is unable to answer. Such input was deliberately omitted from this experiment as it could have influenced the ratings, while the course timetable did not allow for a rounding off and further questions and answers straight after the presentations.

\section{Acknowledgements}

I thank the postgraduate students for participating in the experiment and the staff at the postgraduate centre, Royal South Hants Hospital, for secretarial assistance.

J. Guy Edwards, Honorary Clinical Senior Lecturer, University Department of Psychiatry. Royal South Hants Hospital, Southampton SO14 OYG 